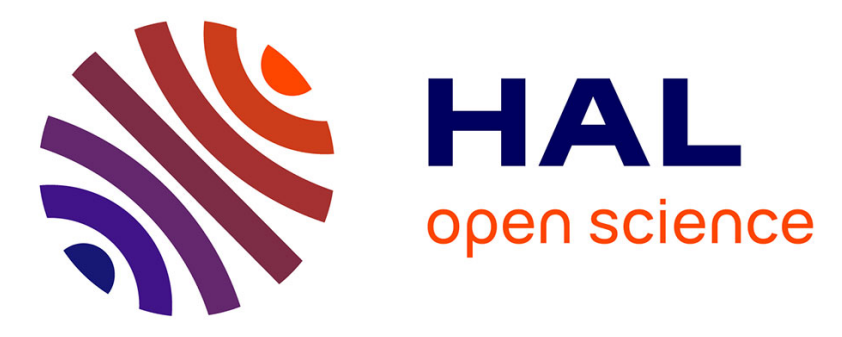

\title{
Micromechanical Modelling of Dynamic Behavior of Advanced Sheet Molding Compound (A-SMC) Composite
}

Houssem Ayari, Mohammadali Shirinbayan, A. Imaddahen, S. Tamboura, H. Ben Daly, Abbas Tcharkhtchi, Joseph Fitoussi

\section{To cite this version:}

Houssem Ayari, Mohammadali Shirinbayan, A. Imaddahen, S. Tamboura, H. Ben Daly, et al.. Micromechanical Modelling of Dynamic Behavior of Advanced Sheet Molding Compound (A-SMC) Composite. Applied Composite Materials, 2020, 27 (3), pp.321-335. 10.1007/s10443-020-09811-9 . hal02885416

\section{HAL Id: hal-02885416 https://hal.science/hal-02885416}

Submitted on 30 Jun 2020

HAL is a multi-disciplinary open access archive for the deposit and dissemination of scientific research documents, whether they are published or not. The documents may come from teaching and research institutions in France or abroad, or from public or private research centers.
L'archive ouverte pluridisciplinaire HAL, est destinée au dépôt et à la diffusion de documents scientifiques de niveau recherche, publiés ou non, émanant des établissements d'enseignement et de recherche français ou étrangers, des laboratoires publics ou privés. 


\title{
Micromechanical Modelling of Dynamic Behavior of Advanced Sheet Molding Compound (A-SMC) Composite
}

\author{
H. Ayari ${ }^{1,2} \cdot$ M. Shirinbayan ${ }^{1,3}$ (D) A. Imaddahen ${ }^{1} \cdot$ S. Tamboura ${ }^{2} \cdot$ H. Ben Daly ${ }^{2}$. \\ A. Tcharkhtchi $^{1} \cdot$ J. Fitoussi ${ }^{1}$
}

Passive safety, particularly in the transport industry, requires maximizing the dissipation of energy and minimizing the decelerations undergone by a vehicle following a violent impact (crash). This paper proposes a strategy for identifying an anisotropic local damage criterion in a moderate dynamic loading for Advanced Sheet Molding Compound (A$\mathrm{SMC}$ ) composite materials. Multi-scale damage modelling based on the Mori-Tanaka approach is put forward. Previously, the results of an experimental campaign carried out on a range of strain rates varying from quasi static to $200 \mathrm{~s}^{-1}$ were used to identify a probabilistic local damage criterion based on Weibull's formulation and integrate the effect of damage at a fiber-matrix interface scale. Therefore, the progressive local damage occurring under a fast loading may be described. A two-step homogenization procedure allows describing the strain rate effect on the stress-strain curves. The model gives also rise to the prediction of the progressive anisotropic loss of stiffness. Comparing between the experimental and numerical results confirms the ability of the proposed approach to describe the visco-damage effect (delay of damage threshold and decrease in damage kinetics) emphasized in A-SMC composites.

Keywords Short-fiber composites · Interface $\cdot$ Multiscale modeling $\cdot$ High strain rate tensile test

\section{Introduction}

The development of composite structures with discontinuous reinforcements is progressing in numerous sectors. These parts can withstand increasing thermomechanical loadings $[1,2]$. Predicting the properties of the structure in terms of strain, damage and rupture becomes essential [3]. This requires knowledge of the behavior laws of these materials. However, the 
variability in the microstructure due to manufacturing processes makes global approaches imprecise. For example, the material flow inside a mold leads to a specific orientation of fibers in certain directions and causes the heterogeneity of the local fiber volume fractions and sometimes even porosity. This main orientation results in local anisotropy, which varies from one location to another [4].

In addition, the recommendations for an automotive structural design require maximizing energy dissipation and minimizing the decelerations undergone by the passengers of the vehicle during violent impacts. In this context, the analysis and prediction of the mechanical behavior of materials and structures under a dynamic loading as a function of the microstructure become very important. Indeed, the effect of the strain rate effect on damage is generally analyzed at different scales, [5-9]. At the local scale, a better understanding of the physical mechanisms directly related to the progressive degradation of the composite materials at a macroscopic scale may contribute to a better formulation of multi-scale damage modelling under dynamic condition. To this end, a specific experimental campaign should be used in order to quantify the threshold and kinetics of each local damage mechanism and its impact on the residual macroscopic properties [4, 10].

A lot of studies dealing with discontinuous fiber-reinforced polymers reveal that fibermatrix interface debonding is generally the main local damage mechanism [8, 10-18]. The experimental multi-scale analysis of tensile tests has shown that interface damage generally begins at the most misoriented fibers versus tensile direction. Indeed, the normal local stress is maximal at this location. Then, it progressively propagates to more oriented fibers. Therefore, fiber-matrix interface damage may be described by coupling the normal and shear stresses at the interface [8].

The experimental work on the dynamic behavior of Sheet Molding Compound (SMC) materials is relatively rare [7, 10, 17-23]. Such studies have demonstrated that the strain rate has a strong influence on the macroscopic mechanical characteristics of the SMC materials of all types. Therefore, the effect of this parameter should be clearly considered for efficient use of the material in structures.

This shows that Young's modulus remains almost insensitive to the strain rate ranging from almost static up to $200 \mathrm{~s}^{-1}$. Moreover, it has been proved that the increase in the strain rate leads to a rise in the threshold and a decrease in the damage kinetics [7]. In fact, the viscous aspect of damage to the fiber-matrix interface is clearly demonstrated by interrupted tests. This aspect is expressed by a delay in the initiation phase and by a decline in the damage kinetics during the propagation phase. Such behavior is described as "visco-damaging"; a concept proposed by Fitoussi et al. [10].

A later study [22] indicated that the other SMC types (advanced-SMC with high volume reinforcement fraction and low-density SMC) showed the same trends. The origin of viscodamage can be attributed to the sensitivity of the fiber-matrix interface to speed and to local dynamic effects. The following trends can be observed to conclude when the loading speed increases [24-28]:

- The slope at the origin of the stress/strain curve increases as viscous effects tend to saturate.

- The stress at break increases.

- The fracture strain decreases. 
The main goal of the developed methodology is to set up a micromechanical model. In order to describe the visco-damage effect described above, the latter should relate the effects of the strain rate on the overall behavior in terms of elastic properties, damage and ultimate characteristics to the local physical mechanisms involved in the initiation and growth of damage.

Thus, a homogenization technique generally based on Eshelby's equivalent inclusion [29] should be used. For polymers reinforced by discontinuous fibers, the approach proposed by Mori and Tanaka [30] and generalized by Benveniste [31] is classically used. This model rests on the detailed description of the microstructure, the orientation distribution, and the volume fraction of fibers. It also considers the mechanical behavior of each phase [32].

Local damage may be introduced into Mori and Tanaka approach by an interface failure criterion given in Weibull's probabilistic form, in order to consider the statistical aspects of local failure [33].

Meraghni and Benzeggagh [34] investigated damage propagation in randomly oriented, discontinuous, fiber reinforced composites. Their experimental studies involving the amplitude analysis of acoustic emission signals and microscopic observations revealed one dominant damage mechanism: the interface damage. Several other authors [7, 10, 35] have confirmed that fiber-matrix interface debonding is the primary damage mechanism in SMC composites.

Jendli et al. [7] qualitatively analyzed the influence of the strain rate on the damage threshold and accumulation. Performing monotonic and interrupted tensile tests at different strain rates, Jendli et al. [12] showed that both damage onset and kinetics are sensitive to the strain rate, such that the interface failure strength increases with increasing strain rate. Similar findings were obtained by Fitoussi et al. [10] and Shirinbayan et al. [18].

Moreover, Fitoussi et al. [36] suggested a micromechanical model based on an equivalent, anisotropic inhomogeneity approach for damaged fibers. Their fiber-matrix interface debonding model was based on a criterion with the linear coupling of the local shear and normal stress on the interface [37]. This work was followed by an extension that considered local strain and stress fluctuations, and a probabilistic interface-strength distribution [33]. Meraghni et al. [38] developed a similar model that combined a microcrack density parameter with fiber-matrix decohesion in order to decrease the fiber strain localization tensor.

Along with their experimental findings, Desrumaux et al. [32] introduced a two-step homogenization damage model for a randomly oriented fiber composite based on a numerically determined Eshelby tensor. In the first step, an anisotropic, equivalently damaged matrix is calculated by considering the undamaged matrix and microcracks. In the second step, the fibers were embedded in the damaged matrix using a numerical Eshelby tensor. A comparable two-step homogenization framework was pursued by Jendli et al. [29] and Kammoun et al. [39], who followed approaches for interfacial decohesion and pseudo-grain sub-regions. Meraghni et al. [40] further developed the probabilistic strength model.

Despite the enormous work already carried out in the context of research on micromechanical modelling under dynamic stresses for polymers reinforced with staple fibers, some shortcomings are still observed. Some of these shortcomings are resolved in this paper.

However, the developed model is based on a quadratic interfacial criterion which is independent of the applied macroscopic three-dimensional load, due to its local nature. Therefore, it can be identified based on a simple dynamic load and it can be applied to an actual structural design for the prediction of the decrease in anisotropic stiffness, which is not the case for Jendli [18] who worked with a limiting stress that varied according to the value of the applied macroscopic strain rate. 
We conclude that the main objective is to identify a numerical form of the evolution of normal local stresses and shear stresses at the fiber-matrix interface under dynamic loading.

\subsection{Description of Material and Experimental Methods}

\subsubsection{Material}

The studied material is an Advanced SMC (A-SMC) composite used in the automotive industry and provided by Plastic Omnium auto exterior services. It consists of an unsaturated vinylester matrix reinforced by a $50 \%$ glass fibers weight content (corresponding to a $38.5 \%$ volume content). The fibers are presented in the form of bundles of constant length $(\mathrm{L}=$ $25 \mathrm{~mm}$ ). Approximately, each bundle contains 250 glass fibers of about $15 \mu \mathrm{m}$ in diameter. Before compression, non-reticulated A-SMC sheets containing randomly oriented bundles are deposited on the mold surface. For more details, the manufacturing process was discussed in the article of Shirinbayan $[17,18]$.

\subsubsection{Methods of Mechanical Characterization}

The mechanical testing samples are cut from the plate to the geometry indicated in Fig. 1. In a previous study [18], a recursive optimization procedure originally proposed by Fitoussi et al. [9] was used to determine the specimen's optimal geometrical parameters for high-speed tensile tests. Indeed, the dynamic loading generates spatiotemporal variations of the stress and strain fields coming from the propagation of mechanical waves. Consequently, an optimization of the specimen geometry is needed in order to assure homogeneous strain field and constant high strain rate during the mechanical test. To this end, Finite Element (FE) simulation using an explicit resolution in order to take into account inertial effects is used. The specific anisotropy of the specimen is considered. This procedure is used an A-SMC and leads to the optimized geometry illustrated in Fig. 1.

Dynamic tensile tests are applied on A-SMC specimens for strain rates ranging from quasistatic to up to $200 \mathrm{~s}^{-1}$. A hydraulic uniaxial tensile machine (Shenck) allowing high speed displacement to control up to $20 \mathrm{~m} / \mathrm{s}$, as presented in Fig. 2. The maximum capacity is five tonnes. A non-contact strain measurement using a high-speed camera (Photron) is performed through monitoring the relative displacement of two marks placed on the surface of the active zone of the tensile specimen (see [18] for more details).

The experimental campaign confirms a drastic reduction in the perturbations due to the propagation of stress waves. Indeed, homogeneous strain fields and a constant high strain rate are obtained. Figure 3 shows that, independently of the strain rate, the macroscopic stressstrain response always evolves according to three consecutive phases. Indeed, after a linear

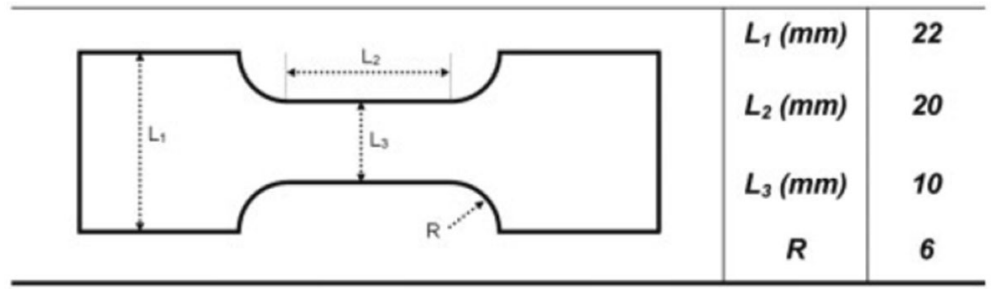

Fig. 1 Specimen dimension obtained from optimized procedure [17, 18] 
a)

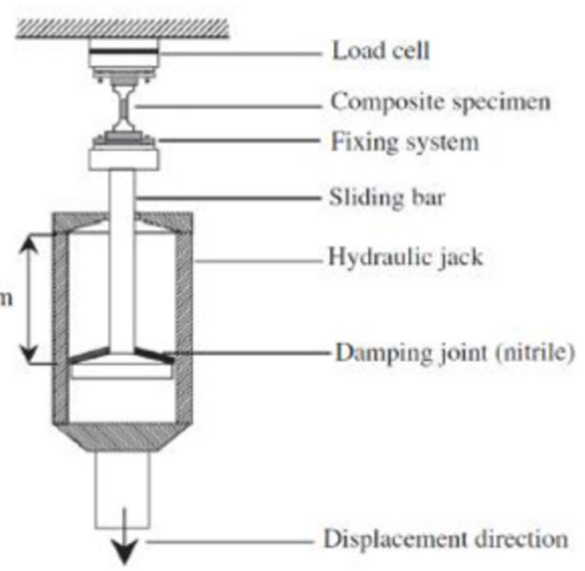

b)

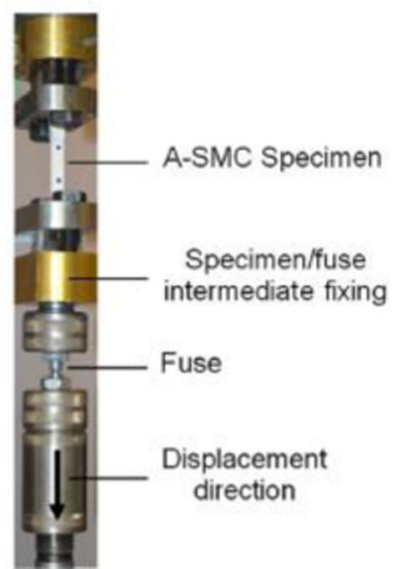

Fig. 2 Hydraulic uniaxial tensile machine (Shenck) and b) Interrupted tensile tests dispositive

elastic stage, the tensile response of A-SMC composites is characterized by a damage threshold corresponding to the first non-linearity. The non-linear phase around the "knee point" is associated with the initiation of damage mechanisms. Finally, an anelastic and relatively linear phase corresponds to the intensification and propagation of the damage phenomena until final failure.

It should be highlighted that for the studied composite material (A-SMC), the elastic stage of the stress-strain curve seems insensitive to the strain rate.

However, a delay of the damage threshold can be noticed when increasing the strain rate. Moreover, damage kinetics (characterised by the slope of the second linear phase) decrease with the strain rate. On the other hand, the failure stress increases at high strain rates. These strain rate effects were largely described in [18]. The authors introduced the concept of the visco-damage effect which was studied at both macroscopic and macroscopic scales (Fig. 4).

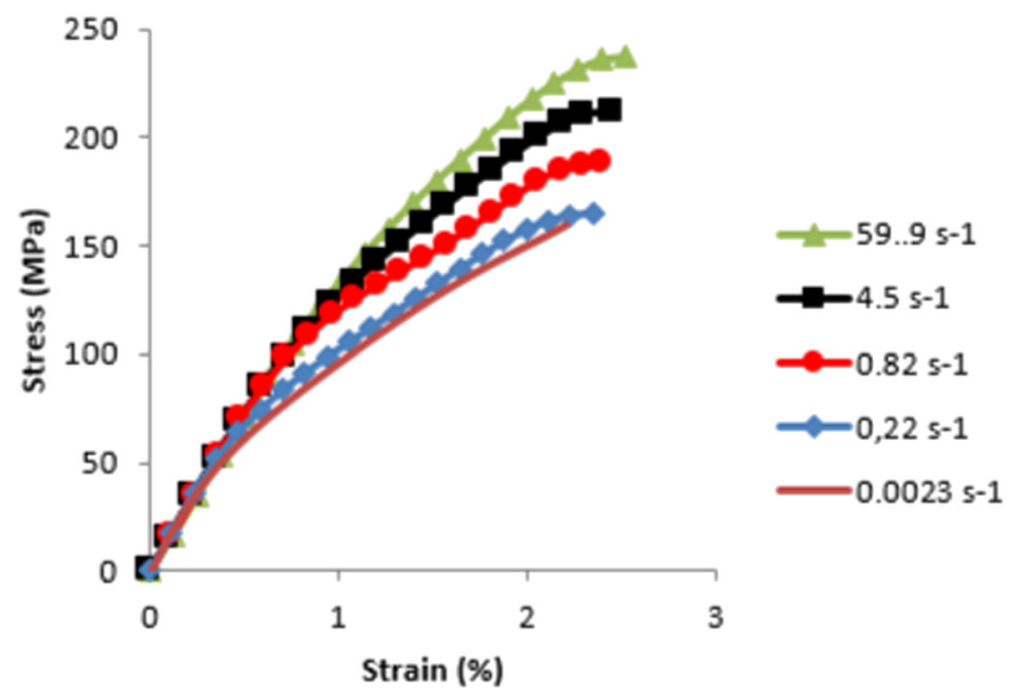

Fig. 3 Effect of strain rate on tensile behavior of A-SMC 


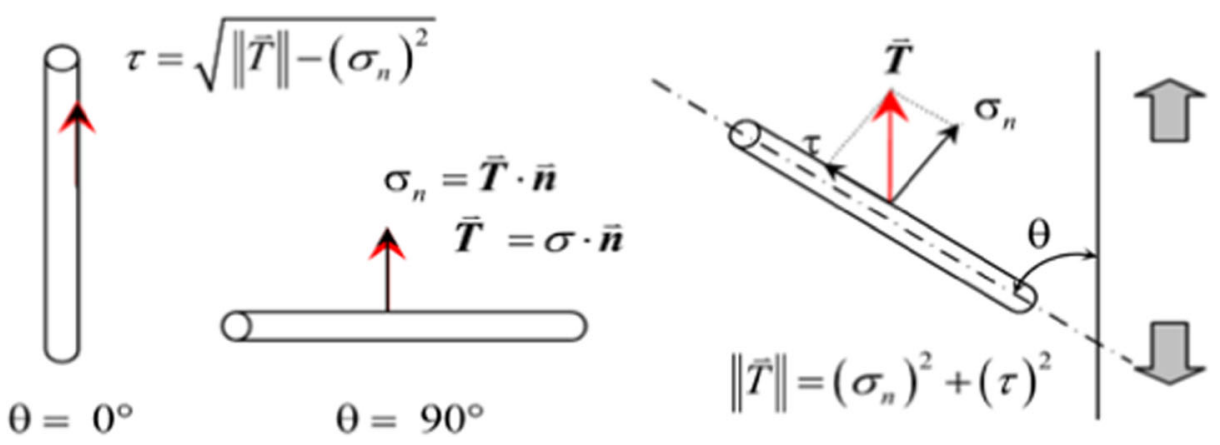

Fig. 4 Stresses exerted on fiber as a function of its orientation, $\theta\left({ }^{\circ}\right)$ relative to direction of loading

At the macroscopic scale, the progressive stiffness reduction of the A-SMC should be characterized by $\mathrm{E}_{0}$ and $\mathrm{E}_{\mathrm{D}}$, which are the Young's modulus of the virgin and damaged materials, respectively.

\subsection{Presentation of the Used Model}

The chosen model can be divided into three essential phases:

1- The estimation of the global stiffness tensor of the material from the mechanical and geometrical properties of the constituents, using the approach of the mean field proposed by Mori and Tanaka, coupled with Eshelby's equivalent inclusion model.

2- The integration of a local damage criterion which allows the estimation and quantification of the density of interfacial cracks. It is worth noting that the average local stress fields inside the inclusions are also estimated and enables identifying the normal and tangential stresses at any fiber-matrix interface point.

3- Modelling of the global behavior integrating the initial anisotropy due to the presence of reinforcements and its evolution caused by damage.

The equations of the micromechanical model are recalled in the following. These equations present the theoretical framework which permits the estimation of the overall mechanical behavior (three-dimensional (3D) stiffness tensor) of the material as well as the local stresses at the fiber-matrix interface and at the matrix level [19]. It was originally proposed by MoriTanaka and subsequently adapted by Benvensite [31]. The reinforcement is modelled as an ellipsoidal inclusion and is characterized by its aspect ratio (length/diameter) and isotropic elastic properties. Eshelby's equivalent inclusion method [41] is used into a classical homogenization method and leads to the formulation of the global stiffness tensor of the composite (Eq. 1):

$$
C^{C o m p}=C^{m}\left[I+f\langle\mathrm{Q}\rangle(I+f\langle(S-I) \mathrm{Q}\rangle)^{-1}\right]^{-1}
$$

where $C^{m}$ et $S$ are respectively the matrix stiffness tensor and Eshelby's tensor, $f$ is the reinforcement volume fraction, and $Q$ presents the mean value of the "pseudo-tensors of localization" defined for each family of reinforcement [19], i, by: 


$$
\mathrm{Q}^{i}=\left(\left(C^{m}-C^{i}\right)\left(S^{i}-I\right)-C^{i}\right)^{-1}\left(C^{i}-C^{m}\right)
$$

In these expressions, $S^{i}$ presents Eshelby's tensor of the $i^{\text {th }}$ reinforcement family, which depends on the mechanical properties of the matrix and the spatial arrangement and geometry of the reinforcement. Tensors $C^{i}$ represent the stiffness of the reinforcement families identified by index i. For A-SMC composites, a reinforcing family is distinguished by its orientation in the plane.

Different studies [41-43] have treated the stress discontinuity just out of the fiber/matrix interface. When the material is subjected to a macroscopic stress $\sum$, the average stress field inside a fiber is given by (Eq. 3):

$$
\sigma^{i}=C^{m}\left(I+\left(S^{i}-I\right) \mathbf{Q}^{i}\right)(I+f\langle(S-I) \mathbf{Q}\rangle) C^{m^{-1}} \Sigma
$$

Considering the condition of the continuity of the normal stress at the fiber-matrix interface [19], the normal stress can be computed as follows:

$$
\sigma_{n}=\vec{T} \cdot \vec{n}
$$

Where $\vec{T}$ corresponds to the stress vector at the considered interfacial point defined by the normal $\vec{n}$.

$$
\vec{T}=\sigma^{i} \cdot \vec{n}
$$

According to Eqs. 4 and 5:

$$
\tau^{i}=\sqrt{\|\vec{T}\|-\left(\sigma_{n}\right)^{2}}
$$

The probability of the fiber-matrix interface failure is given for each family of the fiber orientation $\theta$ by [19]:

$$
P_{r}(\theta, \varphi)=1-\exp \left(-\left(\left(\frac{\sigma}{\sigma_{0}}\right)^{2}+\left(\frac{\tau}{\tau_{0}}\right)^{2}\right)^{m}\right)
$$

where $m$ is a statistic parameter related to the dispersion of the microstructure. The normal stress $\sigma$ and the shear stress $\tau$ depend on the macroscopic stress and orientation of the fiber, the volume fraction, the aspect ratio of the fiber, and the elastic properties of the matrix and the fiber.

Consequently, at each calculation step, $n$, the local interface failure probabilities are calculated and give access to the quantities of fibers damage. As a result, the local state of damage is described at each calculation step, $n$, by:

The proportion of non-damage fibers is as follows [14]:

$$
f_{n}^{N D}=\left(1-P_{r}^{n}\right) * f_{n-1}^{N D}
$$

The proportion of "active fibers" including the "non-damage" ones and a part of the damaged ones which continue participating to the global stiffness is as follows [14]: 


$$
f_{n}^{a c t}=f_{n}^{N D}+k \sum_{i=1}^{n} P_{r}^{i} \cdot f_{i-1}^{N D}
$$

where $k$ is a stiffness contribution parameter evaluated by an FE calculation performed on a unit cell [44].

Two kind of unit cell containing a unique fiber are modelized using the periodic homogenization technique. The first one considers a perfect interface, whereas the second one includes a partially debonded interface. The comparison between the two obtained results leads to an average value of $\mathrm{k}$.

The proportion of micro-cracks which are modelled by penny-shape zero-stiffness heterogeneities is as follows [14]:

$$
f_{n}^{m c}=f_{n-1}^{m c}+h \cdot P_{r}^{n} \cdot f_{n-1}^{N D}
$$

where $h$ corresponds to the ratio between the volume of the penny shape and that of the damage fiber.

\subsection{Micromechanical Modeling of Damage at Fiber-Matrix Interface}

Despite the enormous work already conducted within the research of discontinuous fiber reinforced polymers, some deficiencies still exist. Some of those deficiencies are addressed by the presented model. Few-models, for example, are physically motivated and take the microscale into account, but they are still efficiently applicable to calculations of structural components (e.g., parts that are of interest to the industry [45-48]).

Our model is based on a quadratic interfacial criterion [14, 19, 49] expressed in terms of normal and shear local stresses at the fiber-matrix interface associated to their corresponding failure values. In order to reflect the effect of the strain rate loading at a fiber-matrix interface scale, the local normal and shear failure stresses should progressively increase.

Moreover, the principal aims are to identify the mathematical form of the evolution of the proposed fiber-matrix interface failure criterion parameters.

It should be mentioned that this criterion is independent of the macroscopic tridimensional applied loading, due to its local nature. Therefore, it may be identified on the basis of simple tensile dynamic loading results and applied to a real structure design for anisotropic stiffness reduction prediction, which was not the case for Jendli [20] who worked with a boundary stress that varies from one loading strain rate to another.

The experimental results obtained on SMC composites under a high-speed load show that an applied macroscopic strain rate leads to the progressive diffuse damage of fiber-matrix interfaces. Indeed, at a local scale, the interface zone (or interphase) is subjected to local speed loading [9]. Each interface location is submitted to a specific displacement speed of normal local stresses and of shear $(\sigma$ and $\tau)$. The local amplitude can be evaluated by Eqs. (3-6). Hence, the local interfacial load depends, among other factors, on the microstructure, the imposed macroscopic load and the local orientation of the considered fiber.

As a consequence, we can consider that the local stresses of the interface-interphase ( $\sigma$ and $\tau)$ undergone with a time increment $\Delta t$ by the interface zone can modify the limiting stresses $\left(\sigma_{0}, \tau_{0}\right)($ Eqs. 11 and 12$)$ due to two local phenomena:

- The decohesion of the interface mainly sensitive to the strain rate [48-51] 
- The redistribution of local stresses due to diffuse damage on other interfacial sites

$$
\begin{aligned}
& \sigma_{0}=a^{*} \operatorname{Exp}\left(\frac{b}{\dot{\sigma}}\right)^{c} \text { where } \dot{\sigma}=\frac{\sigma^{n}-\sigma^{n-1}}{\Delta t} \\
& \tau_{0}=d^{*} \operatorname{Exp}\left(\frac{e}{\dot{\tau}}\right)^{f} \text { where } \dot{\tau}=\frac{\tau^{n}-\tau^{n-1}}{\Delta t}
\end{aligned}
$$

where $a, b, c, d, e$ and $f$ are material parameters to be identified.

The parameters of this local criterion are identified by reverse engineering based on the experimental results described in the Sect. 2.

As a result, to take into account, the local effect of the load applied to the apparent resistance of the fiber-matrix interface, we can consider that the associated local failure criterion requires a progressive increase in the parameters of the interfacial resistance $\left(\sigma_{0}\right.$, $\left.\tau_{0}\right)$. This development should relate to:

- Local and tangential interfacial stress amplitudes $(\sigma$ and $\tau)$

- Applied strain rate

- Speed of normal and tangential stresses

\subsubsection{High-Speed Damage Predicting Procedure}

Since the evolution of the parameters of the interfacial resistance is identified, we can use the micromechanical damage model presented above to predict speed damage. To this end, we propose an algorithm illustrated in Fig. 5. The input data include the elastic characteristics of the different phases, the orientation distribution of the fiber, the parameters of the initial interfacial resistance $\left(\sigma_{0}, \tau_{0}\right)$, the imposed macroscopic strain, $\varepsilon^{i m p}$, the applied strain rate, and the time increment $\Delta t$.

The interfacial stress fields $\sigma(\theta, \varphi), \tau(\theta, \varphi)$ can be calculated for each fiber-matrix interface location $(\theta, \varphi)$. Thus, the maximal value of the probability of the interfacial failure can be determined for each fiber orientation so as to calculate the corresponding new volume fractions of undamaged fibers. At the same time, the density distributions of active fibers (always contributing to the composite stiffness) and of interfacial microcracks are calculated. Therefore, first stage homogenization, including active fibers only, is carried out. Then, the second homogenization step permits determining the whole of the damaged composite, including the active fibers and the micro-cracks at the interface of the fiber matrix for the considered number of increments and the imposed macroscopic strain. After the increments, a new value of the applied time is defined, and this procedure is repeated.

The obtained result then relates to the mechanical properties of the damaged composite material. The described approach allows, among other things, estimating the losses in composite stiffness in all directions as the mechanical loading changes, and it allows also clearing the stress-strain curve. 


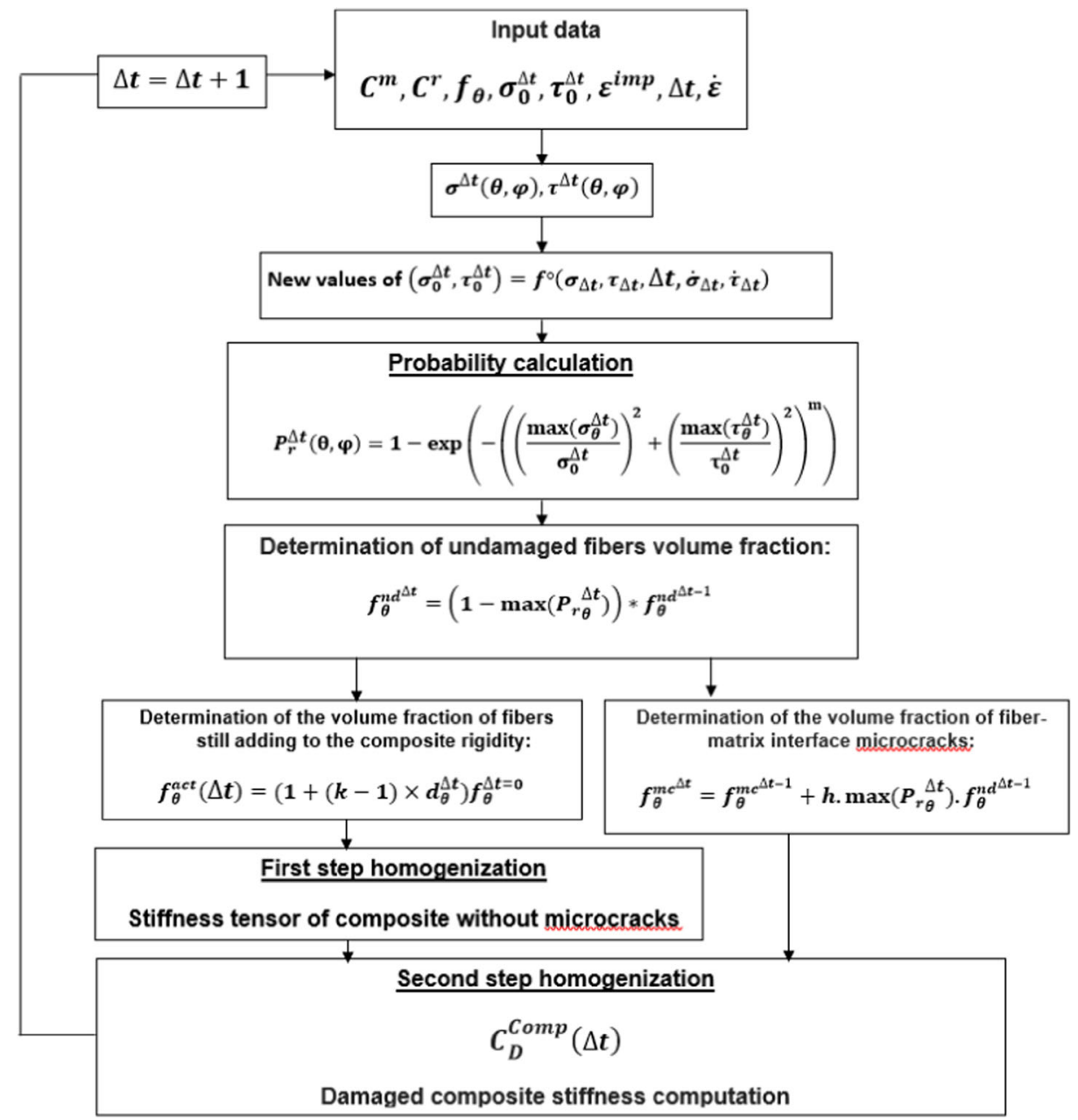

Fig. 5 Micromechanical dynamic damage prediction algorithm

\section{Identification: Results and Discussion}

The procedure described below is based on the local stresses calculated at the fiber/matrix interface. However, as presented in Sect. 3, the multi-scale model (Mori-Tanaka) allows access to local stress fields $(\sigma$ and $\tau$ ) in the fiber and at the fiber/matrix interface from the macroscopic strain applied to the composite RVE.

For a well-defined applied macroscopic strain rate, Fig. 6 depicts the profiles of normal and tangential stresses, respectively, which are calculated for each time increment for $60 \mathrm{~s}^{-1}$.

The main idea of our approach is to identify the evolution of the limit stress at the fibermatrix interface during a periodic loading. As this phenomenon occurs on a local scale, this evolution should be independent of the imposed macroscopic load. Indeed, Eqs. 11 and 12 clearly indicate that the evolution of the interfacial force is linked to the local interfacial stresses $\left(\sigma_{\Delta t} \tau_{\Delta t}\right)$ and to the speed of these stresses $\left(\dot{\sigma}_{\Delta t}, \dot{\tau}_{\Delta t}\right)$ which rise with the increment of the applied time. Once the interfacial stress fields $\sigma(\theta, \varphi), \tau(\theta, \varphi)$ are calculated and their 

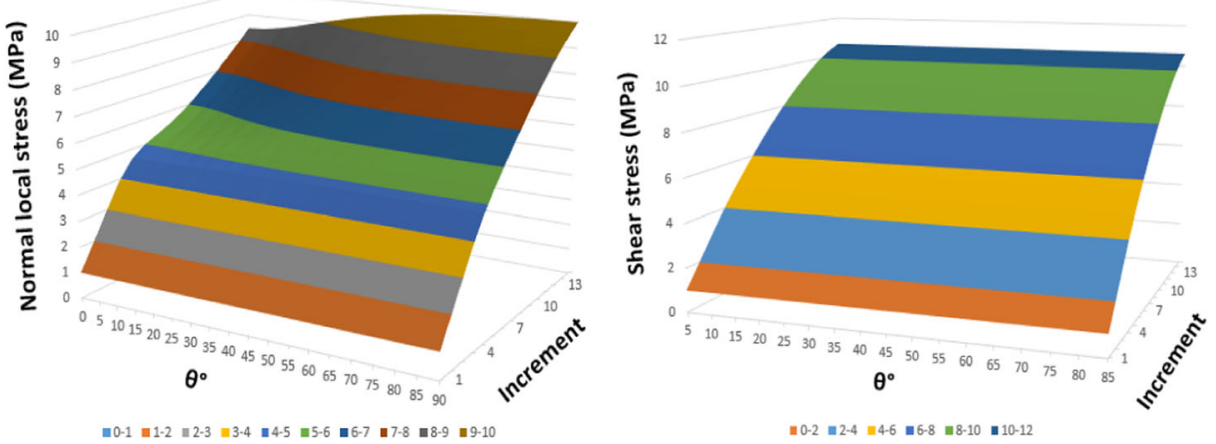

Fig. 6 Normal local stress and shear stress profile for $\theta \in\left[0^{\circ}, 90^{\circ}\right], \varphi=0^{\circ}$

evolution is brought out, then we can directly calculate the limiting stresses $(\sigma 0, \tau 0)$ through (Eqs. 11 and 12) implemented in the model. This allows us to calculate the damaged rigidity matrix during each calculation step where the principle has been already detailed in Fig. 5.

Once the criterion is identified as a function of the strain rate, the modeling procedure, described in the previous paragraphs, allows the stress-strain curves to be simulated for different strain rates [17]. Figure 7 shows simulated stress-strain curves compared to those obtained experimentally for two different strain rates. We can note a good correlation between them for various strain rates. The model identified at the microscopic scale is validated at the macroscopic scale for the tensile tests.

The developed multi-scale model makes it possible to predict the reduction in $3 \mathrm{D}$ stiffness caused by the high-speed load obtained at different crosshead speeds (Fig. 8). Furthermore, the micromechanical model is used to determine the evolution of the macroscopic criterion of damage for an SMC composite subjected to different paths of a 3D loading: proportional and no proportional. A macroscopic law of $3 \mathrm{D}$ visco-damage for an anisotropic material is established taking into consideration the anisotropy evolution due to the multi-axial load. The determination of the macroscopic criterion is therefore based on the obtained experimental data.

According to the model results, we can see that when the strain rate rises, the material resists more. Therefore, the threshold stress increases, which validates our results.
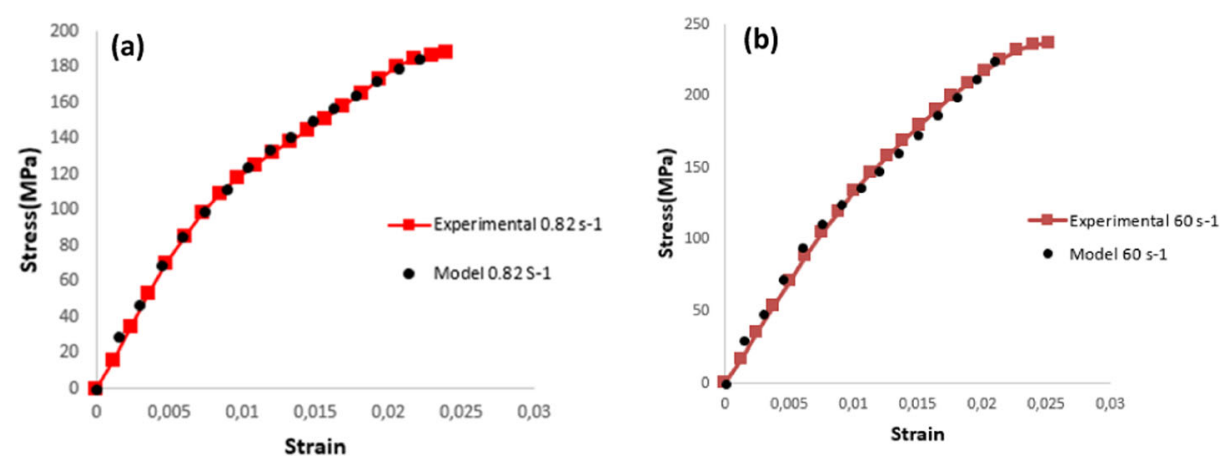

Fig. 7 Comparison of experimental results and modeling at macroscopic: stress-strain curves for two strain rates: (a) 1 and (b) $60 \mathrm{~s}^{-1}$ 

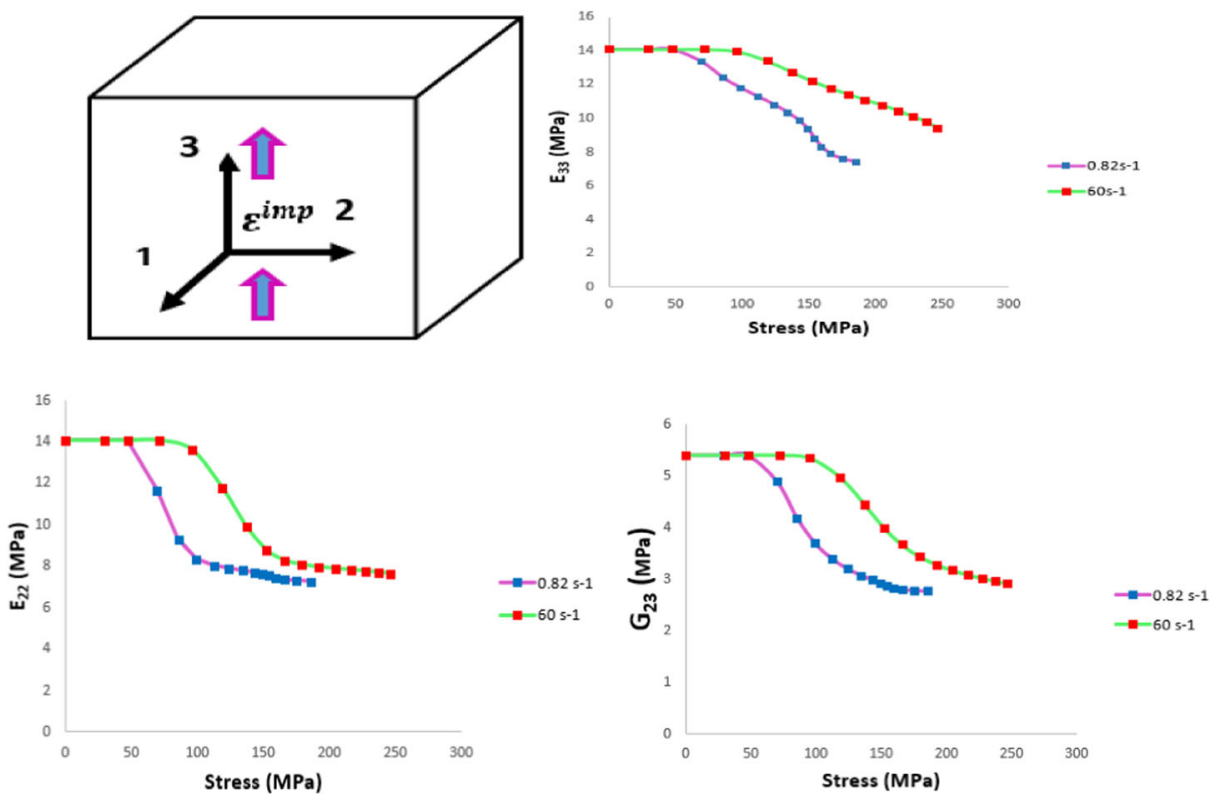

Fig. 8 Predicted stiffness reduction (E33, E22 and G23) at three strain rates $\left(0.82\right.$ and $\left.60 \mathrm{~s}^{-1}\right)$

\section{Conclusion}

The experimental approach has ensured for the A-SMC composite that the strain rate effect has mainly conditioned the threshold and kinetics of deterioration, at the fiber-matrix interface. Indeed, the strain rate effect on the interface failure is got thanks to the proposal of a local statistical criterion sensitive to the strain rate in terms of threshold and kinetics. Identification has been carried out at the local scale, and the model has been validated at the macroscopic scale based on the results of rapid traction. Thus, the work presented in this article is an evolution towards a dynamic version of models statically developed on these materials. The obtained results are in good agreement with the experiments.

The present work constitutes a contribution to the prediction of the macroscopic behavior of staple fiber composites subjected to a dynamic load. In fact, these approaches can be useful for configuring behavior data, which are used in dynamic FE codes. It can be introduced as a law user or it can identify a macroscopic behavior law. Moreover, the micromechanical model can describe the degradation of directional stiffness under a general loading path.

\section{References}

1. Feuillade, V., Bergeret, A., Quantin, J., Crespy, A.: Characterisation of glass fibres used in automotive industry for SMC body panels. Compos. Part A Appl. Sci. Manuf. 37(10), 1536-1544 (2006)

2. Chaturvedi, S.K., Sun, C.T., Sierakowski, R.L.: Mechanical characterization of sheet molding compound composites. Polym. Compos. 4(3), 167-171 (1983)

3. Naebe, M., Abolhasani, M.M., Khayyam, H., Amini, A., Fox, B.: Crack damage in polymers and composites: a review. Polym. Rev. 56(1), 31-69 (2016) 
4. Shirinbayan, M.; Etude du comportement mécanique et de l'endommagement de divers matériaux composites SMC soumis à des chargements de type dynamique, fatigue et dynamique post-fatigue. Thèse de doctorat d'Arts et Métiers ParisTech (2017)

5. Okoli, O.: The effects of strain rate and failure modes on the failure energy of fibre reinforced composites. Compos. Struct. 54, 299-303 (2001)

6. Dear, J.P., Brown, S.A.: Impact damage in reinforced polymeric materials. Compos. Part A: Appl. Sci. Manufact. 34, 411-420 (2003)

7. Jendli, Z., Meraghni, F., Fitoussi, J., Baptiste, D.: Micromechanical analysis of strain rate effect on damage evolution in sheet molding compound composites. Compos. Part A Appl. Sci. Manuf. 35(7-8), 779-785 (2004)

8. Lee, H.K., Simunovic, S.: A damage mechanics model of crack-weakened, chopped fiber composites under impact loading. Compos. Part B: Eng. 33, 25-34 (2002)

9. Fitoussi, J., Meraghni, F., Jendli, Z., Hug, G., Baptiste, D.: Experimental methodology for high strain-rates tensile behaviour analysis of polymer matrix composites. Compos. Sci. Technol. 65, 2174-2188 (2005)

10. Fitoussi, J.: Etude micromécanique de l'influence de l'endommagement à l'interface fibre/matrice sur le comportement des composites organiques à renforts discontinus. Thesis in ENSAM, Paris (1995)

11. Capela, C., Costa, J.D., Ferreira, J.A.M.: Test conditions effect on the fracture toughness of hollow glass micro-sphere filled composites. Strain. 44(2), 141-146 (2008)

12. Jendli, Z., Fitoussi, J., Meraghni, F., Baptiste, D.: Anisotropic strain rate effects on the fibre-matrix interface decohesion in sheet moulding compound composites. Compos. Sci. Technol. 65(3-4), 387-393 (2005)

13. Tamboura, S., Sidhom, H., Baptiste, H., Fitoussi, J.: Fatigue resistance evaluation of SMC R42 composite. Mater. Tech. 89, 3-4 (2001)

14. Laribi M. A., Tamboura S, Fitoussi J, Tcharkhtchi A, H. Ben Dali, Fast fatigue life prediction of short fiber reinforced composites using a new hybrid damage approach: application to SMC Compos. Part B: Eng., Volume 139, 15 April 2018, Pages 155-162

15. Shirinbayan M., Fitoussi J., Meraghni F., Farzaneh S., Surowiec B., Tcharkhtchi A.: Effect of a post-fatigue damage on the residual dynamic behavior of advanced-SMC composites. Appl. Compos. Mater., 1-19 (2019)

16. Shirinbayan, M., Fitoussi, J., Meraghni, F., Laribi, M., Surowiec, B., Tcharkhtchi, A.: Coupled effect of loading frequency and amplitude on the fatigue behavior of advanced sheet molding compound (A-SMC). J. Reinf. Plast. Compos. 36(4), 271-282 (2017)

17. Shirinbayan, M., Fitoussi, J., Bocquet, M., Meraghni, F., Surowiec, B., Tcharkhtchi, A.: Multi-scale experimental investigation of the viscous nature of damage in advanced sheet molding compound (ASMC) submitted to high strain rates. Compos. Part B. 115, 3-17 (2017)

18. Shirinbayan, M., Fitoussi, J., Meraghni, F., Surowiec, B., Bocquet, M., Tcharkhtchi, A.: High strain rate visco-damageable behavior of advanced sheet molding compound (A-SMC) under tension. Compos. Part B. 82, 30-41 (2015)

19. Jendli, Z., Meraghni, F., Fitoussi, J., Baptiste, D.: Multi-scales modelling of dynamic behavior for discontinuous fiber SMC composites. Compos. Sci. Technol. 69, 97-103 (2009)

20. Jendli, Z.: Analyse et modelisation multi echelles du comportement mecanique sous sollicitations rapides de composites SMC. Thesis in ENSAM, Paris (2005)

21. Shirinbayan M, Fitoussi J, Abbasnezhad N, Meraghni F, Surowiec B, Tcharkhtchi A.: Overall mechanical characterization of a low density sheet molding compound (LD-SMC): multi-scale damage analysis and strain rate effect. Compos. Part B: Eng. (2017)

22. Shirinbayan M.: Etude du comportement mécanique et de l'endommagement de divers matériaux composites SMC soumis à des chargements de type dynamique, fatigue et dynamique post-fatigue. Thesis in Ecole nationale supérieure d'arts et métiers- ENSAM, 2017

23. Chaboche, J.L., Gallerneau, F.: An overview of the damage approach of durability modelling at elevated temperature. Fatigue Fract. Eng. 24, 405-418 (2001)

24. Al-Maghribi Abir: Comportement des materiaux composites a fibres courtes: applications a l'impact basse vitesse. Thesis in I.S.A.E Institut Supérieure de l'Aéronautique et de l'Espace, université de Toulouse, 2008

25. Bonnet B.: Comportement au choc de matériaux composites pour applications automobiles. Thesis in Ecole des Mines-Paris

26. Barré, S., Chotard, T., Benzeggah, M.L.: Comparative study of strain rate effects on mechanical properties of glass fibrere inforced thermoset matrix composites. Compos. Part A. 27, 1169-1181 (1996)

27. Cantwell, W.J., Morton, J.: The impact resistance of composite materials. Composites. 22, 347-362 (1991)

28. Sierakwski, R.L.: Strain rate effects in composites. J. Appl. Mech. Part 1. 50, 741-761 (1997)

29. Eshelby, J.D.: The elastic field outside an ellipsoidal inclusion. Proc. R. Soc. Lond. Ser. A. 252, 561-569 (1959) 
30. Tanaka, K., Mori, T.: The hardening of crystals by non-deorming particles and fibers. Acta Metall. 18, 931941 (1970)

31. Benveniste, Y.: A new approach to the application of Mori-Tanaka's theory. Mech. Mater. 6, 147-157 (1987)

32. Desrumaux, F., Meraghni, F., Benzeggagh, M.L.: Generalised Mori-Tanaka sheme to model anisotropic damage using numerical Eshelby tensor. J. Compos. Mater. 35(7), 603-624 (2001)

33. Lee, H.K., Simunovic, S.: A damage mechanics model of crack-weakened, chopped fiber composites under impact loading. Compos. Part B: Eng. 33, 25-34 (2002)

34. Meraghni, F., Benzeggagh, M.L.: Micromechanical modelling of matrix degradation in randomly oriented discontinuous-fibre composites. Compos. Sci. Technol. 55(2), 171-186 (1995). https://doi.org/10.1016 10266-3538(95)00096-8

35. Ben Cheikh Larbi, A., Sai, K., Sidhom, H., Baptiste, D.: Constitutive model of micromechanical damage to predict reduction in stiffness of a fatigued SMC composite. J. Mater. Eng. Perform. 15(5), 575-580 (2006). https://doi.org/10.1361/105994906X124569

36. Fitoussi, J., Bourgeois, N., Guo, G., Baptiste, D.: Prediction of the anisotropic damaged behavior of composite materials: introduction of multilocal failure criteria in a micro-macro relationship. Comput. Mater. Sci. 5, 87-100 (1996). https://doi.org/10.1016/0927-0256(95)00061-5

37. Fitoussi, J., Guo, G., Baptiste, D.: Determination of a tridimensional failure criterion at the fibre/matrix interface of an organic-matrix/discontinuous-reinforcement composite. Compos. Sci. Technol. 56(7), 755760 (1996). https://doi.org/10.1016/0266-3538(96)00017-6

38. Meraghni, F., Blakeman, C.J., Benzeggagh, M.L.: Effect of interfacial decohesion on stiffness reduction in a random discontinuous-fibre composite containing matrix microcracks. Compos. Sci. Technol. 56(5), 541555 (1996). https://doi.org/10.1016/0266-3538(96)00039-5

39. Kammoun, S., Doghri, I., Brassart, L., Delannay, L.: Micromechanical modeling of the progressive failure in short glass-fiber reinforced thermoplastics - first pseudo-grain damage model. Compos. Appl. Sci. Manuf. 73, 166-175 (2015). https://doi.org/10.1016/j.compositesa.2015.02.017

40. Meraghni, F., Desrumaux, F., Benzeggagh, M.L.: Implementation of a constitutive micromechanical model for damage analysis in glass mat reinforced composite structures. Compos. Sci. Technol. 62(16), 2087-2097 (2002). https://doi.org/10.1016/S0266-3538(02)00110-0

41. Eshelby, J.D.: The determination of the elastic field of an ellipsoidal inclusion and related problems. Proc. Roy. Soc. Lond. A. 241, 376-396 (1957)

42. Taya, M., Mura, T.: On stiffness and strength of an aligned short-fiber reinforced composite containing fiber-end cracks under uniaxial applied stress. J. Appl. Mech. 48, 361-367 (1981)

43. Morozov, E.V., Morozov, K.E., Selvarajalu, V.: Damage model development for SMC composites. Compos. Struct. 62, 375-380 (2003)

44. Fitoussi, J.: Etude micromécanique de l'influence de l'endommagement à l'interface fibre/matrice sur le comportement des composites organiques à renforts discontinus. Thesis in ENSAM, Paris (1995)

45. Bruderick M., Denton D., Shinedling M.: Applications of Carbon Fiber SMC for the Dodge Viper, Proceedings to Automotive Composites Conference \& Exhibition(ACCE), Detroit, 2013

46. Jansen, C.: Isogrid-stiffened automotive suspension control arm. JEC Compos. Mag. 6(82), 38 (2013)

47. Hangs B., Bücheler D., Karcher M., Henning F.: High-Volume Production of Structural Automobile Parts: Comparative Study of Relevant Composite Technologies, FIPCO Functional Integrated Plastic Components, 2016

48. Fitoussi, J., Guo, G., Baptiste, D.: A statistical micromechanical model of anisotropic damage for smc composites. Compos. Sci. Technol. 58(5), 759-763 (1998)

49. Ayari, H., Fitoussi, J., Imaddahen, A., Tamboura, S., Shirinbayan, M., Dali, H.B., et al.: Two hybrid approaches to fatigue modeling of advanced-sheet molding compounds (A-SMC) composite. Appl. Compos. Mater. (2020). https://doi.org/10.1007/s10443-019-09793-3

50. Imaddahen M.A., Fitoussi J., Ayari H., Shirinbayan M., Foucard M., Tcharkhtchi A.: Overall investigation of mechanical behavior of short fiber reinforced polypropylene under monotonic and fatigue loading. Submitted to App. Compos. Mater. 2020

51. Tamboura, S., Ayari, H., Shirinbayan, M., Laribi, M.A., Bendaly, H., Sidhom, H., Tcharkhtchi, A., Fitoussi, J.: Experimental and numerical multi-scale approach for sheet-molding compound composites fatigue prediction based on fiber-matrix interface cyclic damage. Int. J. Fatigue. 135, 105526 (2020) 


\section{Affiliations}

H. Ayari ${ }^{1,2} \cdot$ M. Shirinbayan ${ }^{1,3} \cdot$ A. Imaddahen ${ }^{1} \cdot$ S. Tamboura ${ }^{2} \cdot$ H. Ben Daly ${ }^{2} \cdot$ A. Tcharkhtchi $^{1} \cdot$ J. Fitoussi ${ }^{1}$

H. Ayari

houssem.ayari@ensam.eu

A. Imaddahen

mohamed-amine.imaddahen@ensam.eu

S. Tamboura

sahbi.tamboura@gmail.com

H. Ben Daly

hachmi.bdaly@gmail.com

A. Tcharkhtchi

abbas.tcharkhtchi@ensam.eu

J. Fitoussi

joseph.fitoussi@ensam.eu

1 Arts et Metiers Institute of Technology, CNAM, PIMM, HESAM University, F-75013 Paris, France

2 University of Sousse, Ecole Nationale d'Ingénieurs de Sousse, LMS, Pôle technologique, Route de Ceinture, 4054 Sousse, Tunisia

3 Arts et Metiers Institute of Technology, CNAM, LIFSE, HESAM University, F-75013 Paris, France 